\title{
Prevention of Central Line-Associated Bloodstream Infections Through Educational Interventions in Adult Intensive Care Units: A Systematic Review
}

Maria Foka ${ }^{1}$, Eleni Nicolaou ${ }^{1}$, Theodoros Kyprianou ${ }^{1}$, Lakis Palazis ${ }^{1}$, Maria Kyranou ${ }^{2}$, Elizabeth Papathanassoglou ${ }^{3}$, Ekaterini Lambrinou ${ }^{2}$

1. Internal Medicine, Nicosia General Hospital, Nicosia, CYP 2. Faculty of Nursing, Cyprus University of Technology, Limassol, CYP 3. Faculty of Nursing, University of Alberta, Edmonton, CAN

Corresponding author: Maria Foka, fokamaria1@gmail.com

\begin{abstract}
Central line-associated bloodstream infections (CLABSIs) represent a severe systemic threat to patients admitted in ICUs and contribute to increased mortality, prolonged length of stay in ICUs, and increased costs. The majority of CLABSIs are preventable. The current systematic review aimed to investigate the effectiveness of educational methods on CLABSI rates in adult ICUs.
\end{abstract}

A systematic literature search was conducted using the electronic databases of Medline, Cumulative Index to Nursing and Allied Health Literature (CINAHL) Plus, and Cochrane Database of Systematic Reviews for studies published from the beginning of 1995 to March 2020. The terms used for the search were as follows: central venous catheters, infection, central line-associated bloodstream infections, intensive care unit, and education intervention in all possible combinations and using the word 'and' between them. Data were extracted independently and crosschecked by two authors using a standard data collection form. The quality of the studies included in the review was assessed using the Methodological Index for Non-randomized Studies (MINORS).

The current systematic review included 27 interventional studies of central line insertion or maintenance or both in adult ICU settings with documentation of the CLABSI incidence expressed per 1,000 catheter days. A large deviation between the length of time and type of educational interventions was found.

Statistical significance was found in all studies (except one) in terms of CLABSI reduction despite the large variation of the length or the type of the educational intervention. Continuing education on infection prevention may be necessary to maintain the post-intervention results and improve clinical outcomes.

Review began 06/16/2021 Review ended 08/14/2021 Published 08/18/2021

\section{() Copyright 2021}

Foka et al. This is an open access article distributed under the terms of the Creative Commons Attribution License CC-BY 4.0., which permits unrestricted use, distribution, and reproduction in any medium, provided the original author and source are credited.
Categories: Infectious Disease, Epidemiology/Public Health

Keywords: central venous catheters, infection, central line associated bloodstream infections, intensive care unit, education, intervention

\section{Introduction And Background}

Central venous catheters (CVCs) are the most important devices used in ICU patients, and they enable the administration of medications, fluids, and blood products directly to the central venous system as well as hemodialysis therapy and hemodynamic monitoring [1]. Although they are extremely necessary tools, CVCs can expose critically ill patients to the risk of central line-associated bloodstream infections (CLABSIs). CLABSIs are defined as bloodstream infections with an onset of at least 48 hours after the insertion of a central catheter, which is not related to another site [2]. These infections are associated with increased mortality and morbidity, increased length of stay, and increased hospitalization cost [3-7].

Studies have shown that simple interventions such as hand hygiene, maximal sterile barriers during catheter insertion, chlorhexidine skin disinfection, optimal catheter site selection, and daily review of line necessity with prompt removal of unnecessary lines can decrease the risk of CLABSIs [1,8-10]. Nevertheless, the International Nosocomial Infection Control Consortium (INICC) has stated that the pooled incidence of CLABSIs in INICC ICUs (ie, in Africa, Asia, Europe, and Latin America) is 4.9 infections per 1,000 central-line days, and it is nearly five times higher than those reported in the USA [11].

The latest data shows that regardless of the availability of evidence-based interventions summarized in the guidelines [12,13], CLABSI rates remain very high (2.7 per 1,000 catheter days) [14]. Bion et al. [9] concluded that the implementation of central-line insertion and maintenance bundles, which were first implemented by Pronovost et al. [8], significantly reduced CLABSI incidence in ICUs. Despite the availability of evidencebased interventions and recommendations [15], the implementation of prevention strategies is usually 
insufficient due to reasons associated with low staff awareness, poor understanding of or disagreement with existing knowledge, failure to change institutional practice, and the lack of resources [16,17].

Several educational interventions such as lectures, seminars, simulations have been organized with the aim to reduce CLABSI rates [1]. However, their effectiveness has not been fully assessed. The present systematic review examines the impact of educational interventions on CLABSI rates in adult ICUs. The association between effectiveness and several characteristics of educational programs is also discussed. We relied on the hypothesis that educational interventions will have a positive effect on the prevention of CLABSIs.

\section{Review}

\section{Search strategy}

A comprehensive literature review of Medline, Cumulative Index to Nursing and Allied Health Literature (CINAHL) Plus, and Cochrane Database of Systematic Reviews was conducted for studies published from the beginning of 1995 to March 2020. The search was conducted during February and March 2020.

Specifically, Medline was systematically searched through a combination of search terms: (((("Central Venous Catheters"[Mesh]) OR ("Central Venous Catheter"[Title/Abstract] OR CVC [Title/Abstract] OR "central line catheter"[Title/Abstract]))) AND (("Infection"[Mesh]) OR Infection[Title/Abstract]))) OR ("central line associated bloodstream infections" or clabsi))) AND (("Intensive Care Units"[Mesh]) OR (icu[Title/Abstract] OR "intensive care unit"[Title/Abstract] OR "critical care"[Title/Abstract])))) AND (("Education"[Mesh]) OR (education[Title/Abstract] OR learning[Title/Abstract] OR teaching[Title/Abstract])). Also CINAHL Plus with Full Text was searched (1995-March 2020) through a combination of search teams: ((MM "Central Venous Catheters" OR "Central Venous Catheter" OR CVC OR "central line catheter")) AND ((MM "Infection" OR Infection OR "central line associated bloodstream infections" or clabsi)) AND ((MM "Intensive Care Units" OR icu OR "intensive care unit" OR "critical care")) AND ((MM "Education" OR education OR learning OR teaching)). Cochrane Database of Systematic Reviews was systematically searched (1995-March 2020) through a combination of search teams: ("Central Venous Catheter" OR CVC OR "central line catheter") AND (Infection OR "central line associated bloodstream infections" or CLABSI) AND (icu OR "intensive care unit" OR "critical care") AND (education OR learning OR teaching). Extra studies were identified via reference lists and manually. Words used for the search were: central venous catheters, infection, central line associated bloodstream infections, intensive care unit, and education intervention in all possible combinations.

\section{Study selection}

Predefined selection criteria were set as follows.

Studies were included if:

- They reported educational interventions only for central venous lines (insertion or maintenance or both)

· They involved only adult ICU setting

- They documented CLABSI incidence expressed per 1,000 catheter days

- They made a comparison using a randomized or non-randomized study design, or an interrupted times series (ITS)

- They described an intervention (ie, lecture, simulation, seminar, workshop, feedback, bundle, checklist, etc.) to reduce CLABSI rates

Reviews, editorials, congress abstracts, or studies that did not report CLABSI incidence were excluded. We used studies in the English language only.

\section{Inclusion criteria}

We included all randomized controlled trials, studies that provided details on before and after the implementation of infection prevention control, as well as interrupted time-series analyses. Studies that examined the effectiveness of an educational intervention targeted at healthcare personnel for CLABSI prevention were selected. The primary outcome was the incidence of CLABSI. Studies that did not report the incidence of CLABSI as an outcome were excluded.

\section{Data extraction}

Data were extracted independently and crosschecked by authors using a standard data collection form. Author names, year of publication, sample size, settings, design, duration of the study, description of the intervention, the number of infections, and CVC days were among the extracted data. In case of discrepancies, a consensus was reached by discussion. 


\section{Cureus}

\section{Quality assessment}

We assessed the methodological quality of every trial for the risk of bias using the Methodological Index for Non-randomized Studies (MINORS) [18]. It consists of 12 questions (items) that evaluate the methodological and scientific value of published articles. Eight questions were selected for methodological assessment for non-randomized studies (A clearly stated aim, Inclusion of consecutive patients, Prospective collection of data, Endpoints appropriate to the aim of the study, Unbiased assessment of the study endpoint, Follow-up period appropriate to the aim of the study, Loss to follow-up less than 5\%, Prospective calculation of the study size) and four additional questions in the case of comparative studies (An adequate control group, Contemporary groups, Baseline equivalence of groups, Adequate statistical analyses).

The items were scored as follows: 0 (not reported), 1 (reported but inadequate), or 2 (reported and adequate). The global ideal score was set as 16 for non-comparative (non-randomized studies) and 24 for comparative studies. All studies selected (27 studies) were non-comparative (non-randomized studies) with a top score of 16 points (Table 1) [5,19-44]. 


\section{Cureus}

\begin{tabular}{|c|c|}
\hline Study & MINORS score \\
\hline Mazi et al. (2014) & $6 / 16$ \\
\hline Guerin et al. (2010) & $7 / 16$ \\
\hline Ong et al. (2011) & $7 / 16$ \\
\hline Walz et al. (2015) & $8 / 16$ \\
\hline Perez Parra et al. (2010) & $8 / 16$ \\
\hline Azim et al. (2019) & $8 / 16$ \\
\hline Santana et al. (2008) & $8 / 16$ \\
\hline Galpern et al. (2008) & $8 / 16$ \\
\hline Lobo et al. (2010) & $9 / 16$ \\
\hline Barsuk et al. (2009) & $9 / 16$ \\
\hline llan et al. (2012) & $9 / 16$ \\
\hline Burden et al. (2012) & $9 / 16$ \\
\hline Render et al. (2011) & $9 / 16$ \\
\hline Paquet et al. (2019) & $9 / 16$ \\
\hline Leblebicioglu et al. (2013) & $9 / 16$ \\
\hline Exline et al. (2013) & $10 / 16$ \\
\hline Rosenthal et al. (2010) & 10/16 \\
\hline Marra et al. (2010) & 10/16 \\
\hline Alkhawaja et al. (2019) & $10 / 16$ \\
\hline Coopersmith et al. (2004) & 10/16 \\
\hline Rosenthal et al. (2018) & 10/16 \\
\hline Warren et al. (2004) & 10/16 \\
\hline Park et al. (2017) & 11/16 \\
\hline Hansen et al. (2014) & 12/16 \\
\hline Khalid et al. (2013) & 12/16 \\
\hline Jaggi et al. (2013) & $12 / 16$ \\
\hline Allen et al. (2014) & $13 / 16$ \\
\hline
\end{tabular}

\section{TABLE 1: Studies and MINOR scores}

MINORS: Methodological Index for Non-randomized Studies

\section{Results}

The search algorithm yielded 339 potentially relevant articles (Medline, CINAHAL, Cochrane Database of Systematic Reviews). Among them, we found duplication of 14 studies; 16 were not in the English language, 17 were editorials, reviews, or guidelines, 34 were irrelevant to the subject, and in three articles, full-text was not available; 94 were not associated with ICU settings ( $\mathrm{n}=94$ studies) and 134 were not before/after CLABSI rate methodology. Therefore, they were excluded. The remaining 27 studies met the inclusion criteria and were included in the study (Figure 1) [5,19-44]. 


\section{Cureus}

339 records identified through database searching

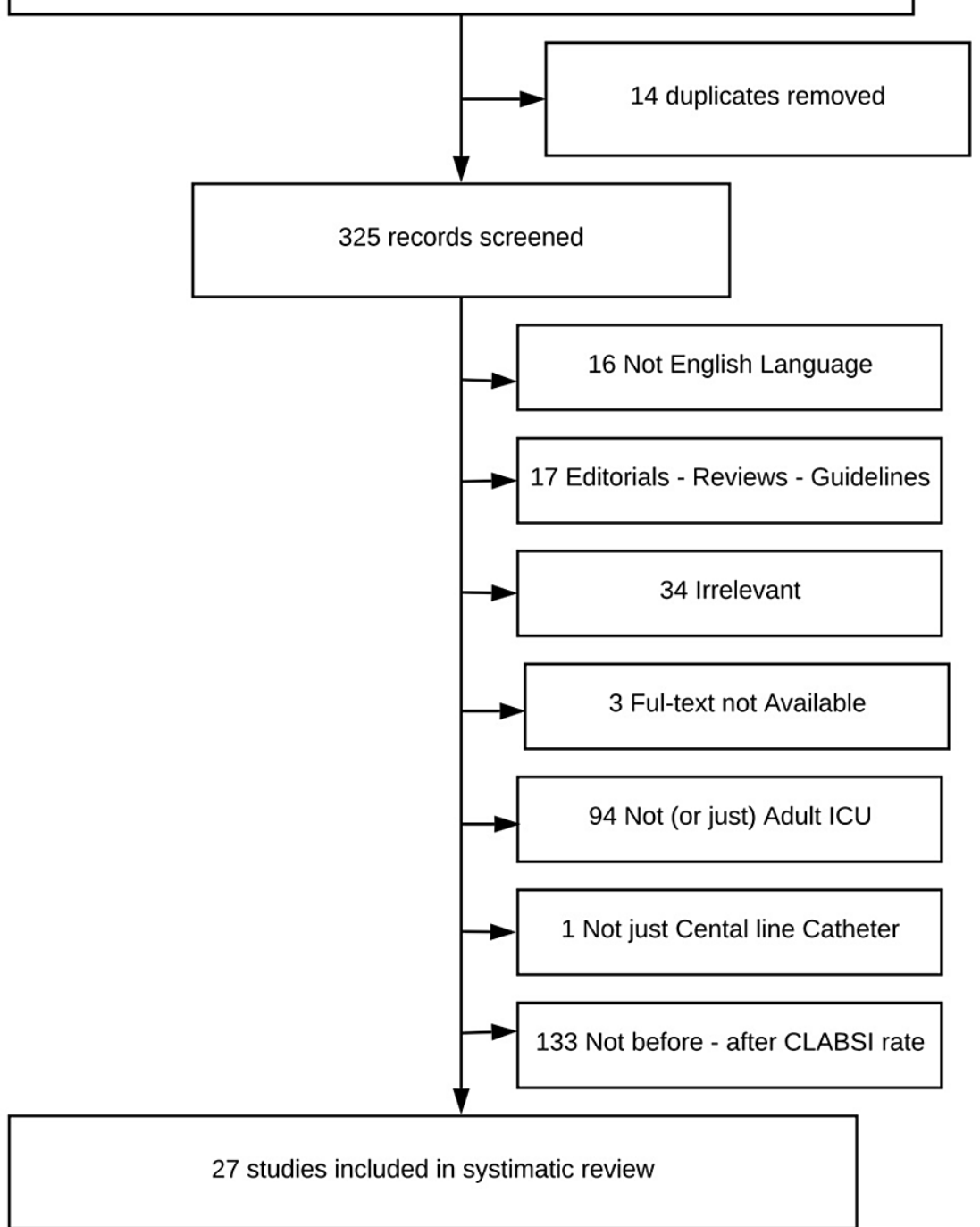

FIGURE 1: Flow diagram illustrating the inclusion of studies

CLABSI: central line-associated bloodstream infection

Study Characteristics

The characteristics of the studies included are summarized in Table 1 . All studies were educational interventions (ie, lecture, simulation, seminar, workshop, feedback, bundle, checklist, etc.) for central lines (insertion or maintenance or both) in an adult ICU setting, with documentation of the CLABSI incidence expressed per 1,000 catheter days, pre-and post-intervention.

Ten studies were conducted in US institutions [5,19-27]; the remaining were conducted in Brazil $(n=3)$ [2830], Korea ( $\mathrm{n}=1)$ [31], Saudi Arabia $(\mathrm{n}=2)$ [32,33], Germany $(\mathrm{n}=1)$ [34], India $(\mathrm{n}=2)$ [35,36], Turkey $(\mathrm{n}=1)$ [37], Canada $(n=3)$ [38-40], Spain $(n=1)$ [41], Bahrain $(n=1)$ [42], and Argentina $(n=1)$ [43]. One study was conducted in 15 countries by the INICC [44]. All studies were undertaken in adult ICUs ( $\mathrm{n}=27)$ [5,19-44].

Two studies were associated with surgical ICUs $(\mathrm{n}=2)[25,31]$ and five studies with medical ICUs $[26,29,35,39,42]$. Five studies were undertaken in both surgical and medical ICUs $[22,23,28,30,40]$. One study was conducted in trauma ICU [32]. The remaining studies were undertaken in general ICUs ( $\mathrm{n}=15)[5,19$ $21,24,27,33,34,36-38,41-44]$. Three of them focused only on the physicians as the target population for the intervention $[5,22,40]$, while the remaining 24 studies focused on both physicians' and nurses' groups (Table 2). 


\section{Cureus}

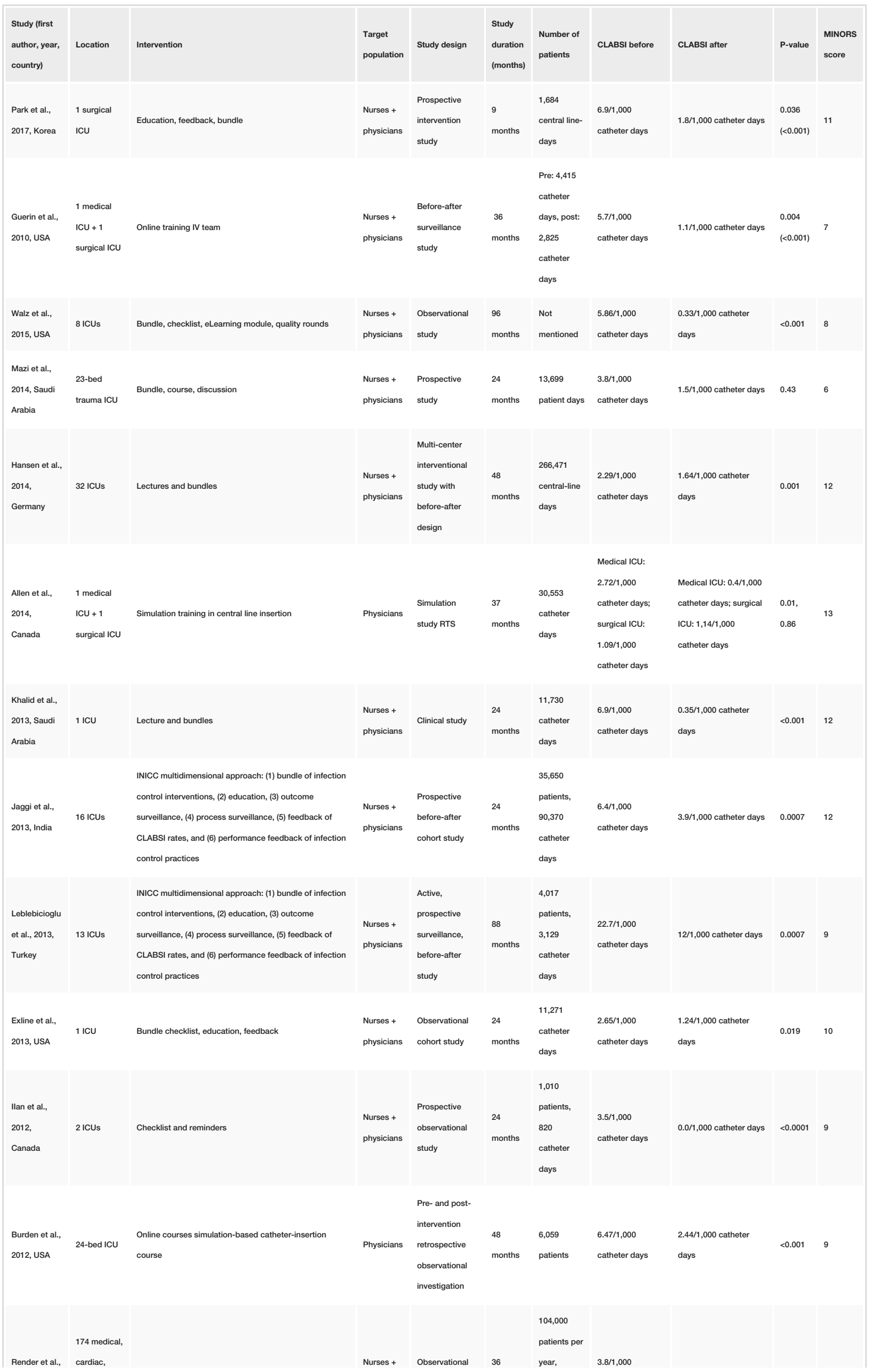




\section{Cureus}

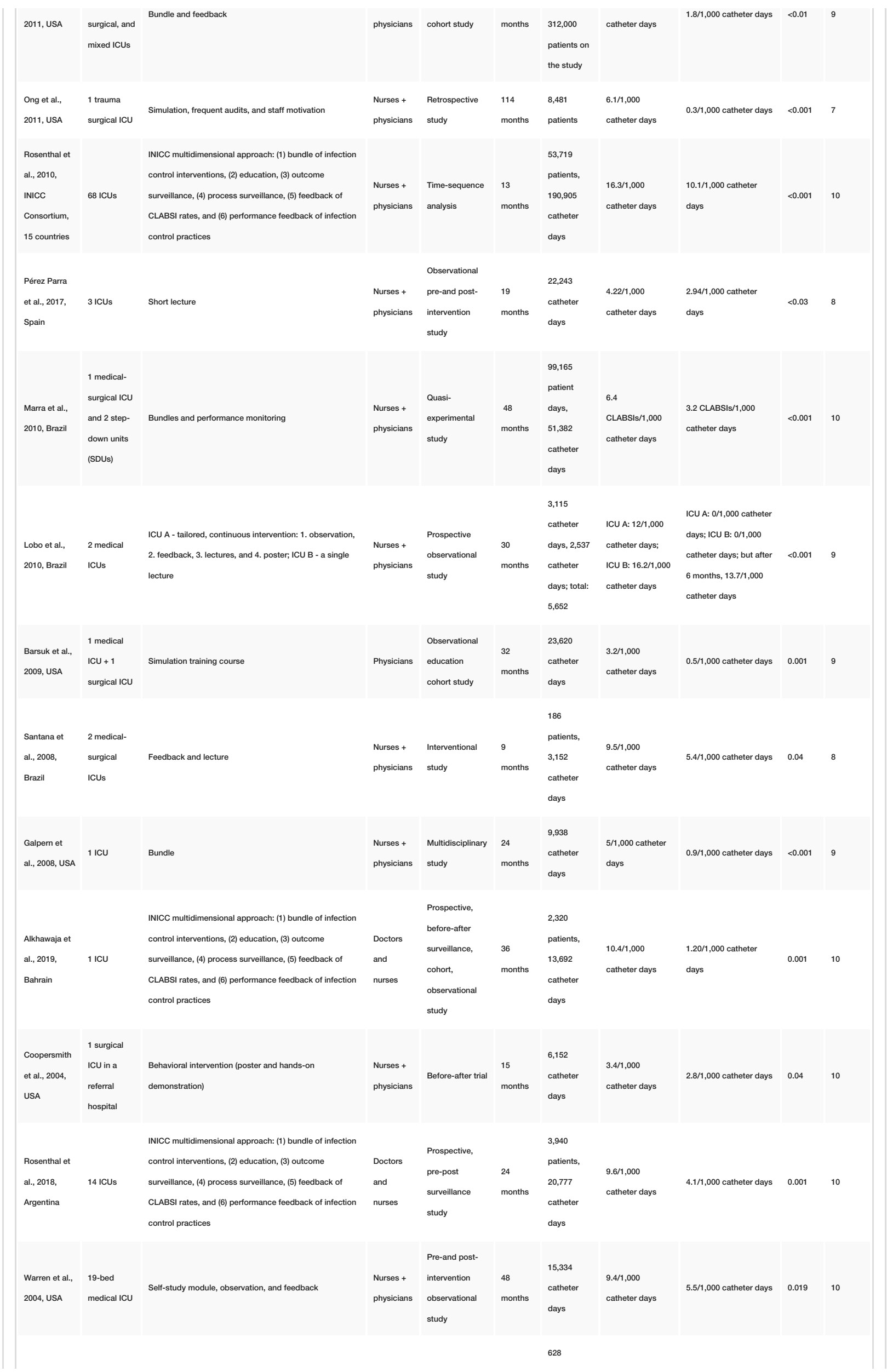




\section{Cureus}

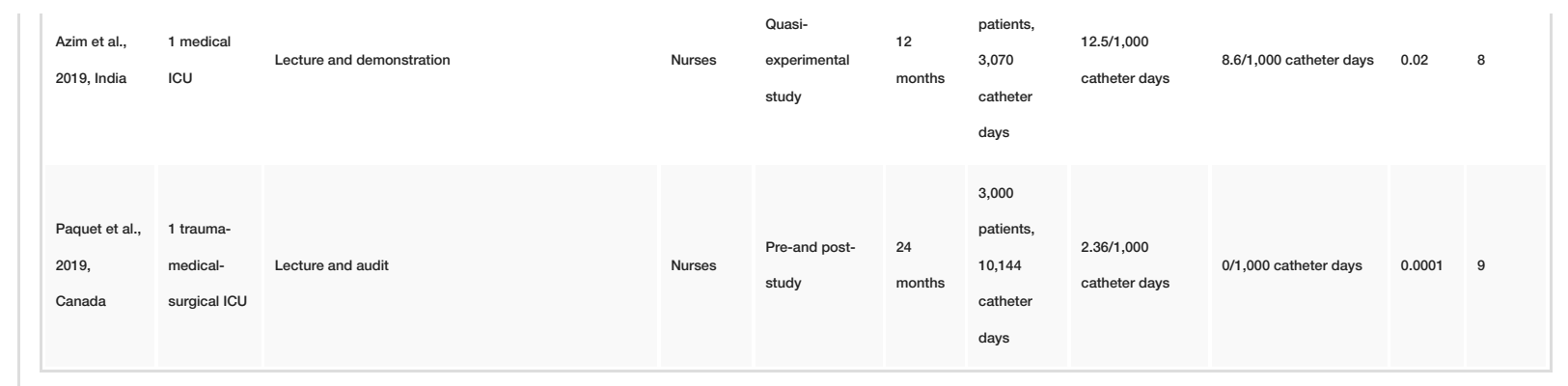

\section{TABLE 2: Summary of study characteristics}

CLABSI: central line-associated bloodstream infection; INICC: International Nosocomial Infection Control Consortium; MINORS: Methodological Index for Non-randomized Studies

Description of Interventions

The educational interventions varied according to the study, but they all used a combination of different modalities. The most common educational tools were for bundles alone $[11,24,31]$, or in combination with other interventions. Three studies used bundles in combination with lectures $[28,33,34]$, five studies used the INICC multidimensional approach [36,37,42-44], three studies [5,22,40] used simulation training only for physicians in central line insertion. Other interventions used were education, bundles, and feedback checklist [19], bundles and feedback [20], bundles, courses, and discussion [32], checklist and remainder [38], bundles, checklists, eLearning modules, and quality rounds [27], online courses and checklists [5], simulation training, frequent audits, and staff motivation [21], short lectures [41], bundles and performance monitoring [28], feedback and lectures [30], lectures and bedside demonstration [35], lectures and audits [39], observation, feedback, lectures, and posters [29], behavioral interventions (posters and hands-on demonstration) [25], and self-study module, observation, and feedback [26]. The duration of each intervention was also highly variable, ranging from one-day lecture [41] to sustained interventions lasting up to nine months [30] and even years [21]. Bundles used in the studies were associated with CVC insertion and maintenance.

Efficacy of Interventions

All studies included in this review reported CLABSI rates before and after an educational intervention. Only one study included in this review did not find a statistically significant reduction in CLABSI rates after the implementation of the intervention [34]. All the other included studies found evidence for the substantial efficacy of the educational intervention.

\section{Durability of Intervention Effect}

The sustainability of the intervention effect seems to be associated with longer study duration and multidimensional approaches. In the study by Walz et al. [27], interventions began in 2004 and lasted until 2011. The intervention includes bundles, checklists, an eLearning module, and quality rounds. The initial CLABSI rate was 5.86 per 1,000 catheter days (2004), which was reduced to 0.33 by $2012(\mathrm{p}<0.0001)$.

A CLABSI rate reduction was also observed in Ong et al.'s [21] interventions, which began in 2001 and lasted until 2009. It included standardization of line insertion and maintenance processes, the development of a mandatory education program incorporating line insertion simulation practice sessions, frequent audits, and ICU staffing modifications. The CLABSI rate was 6.1 per 1,000 catheter days (2004), which was reduced to 0.3 per 1,000 catheter days by $2012(\mathrm{p}<0.0001)$.

\section{Assessment of Methodologic Quality of Included Studies}

The study rationale was easily identifiable in all studies [5,19-44]. In all of them, the study design was appropriate for the study question, and the majority described the design in sufficient detail. However, two studies $[29,40]$ chose a similar comparison group for their study. None of the studies was a cluster randomized controlled trial.

The setting in all of the studies under which the interventions were carried out was well described. However, a detailed description of the follow-up period appropriate to the aim of the study was found in only two studies $[29,31]$. The methods used for statistical testing were described in all studies (Table 2).

\section{Discussion}


Our systematic review shows that a variety of educational strategies have been studied for the prevention of CLABSI, which targeted nurses and physician groups. We found that the systematic application of educational interventions can decrease rates of CLABSI; however, it is difficult to determine the most effective educational intervention due to the presence of a variety of approaches.

Studies from developing countries $[36,37,43,44]$ that implemented the INICC multidimensional approach showed a statistically significant reduction in the CLABSI rates. Educational interventions that were undertaken in developing countries found substantial benefits similar to the studies that were undertaken in developed countries. Although the educational strategies were highly variable and multidimensional, most of the interventions emphasized the need for the adoption of insertion and maintenance bundles for CLABSI prevention.

In all of the studies included in the current review, nurses were the main target population except in three $[5,22,40]$. This probably shows the importance given to the nurses' role in the insertion and maintenance of CVCs. Nurses are providing continuing care to ICU patients and have a key role in the quality of care provided [45].

The simplest intervention found was a short lecture of 15 minutes among the 10 main points of Infectious Diseases Society of America/Centers for Disease Control and Prevention (IDSA-CDC) guidelines for the prevention of intravascular catheter-related infections, which surprisingly led to a statistically significant decrease in CLABSI rates $(\mathrm{p}<0.03)$ [41].

The lack of a detailed description of the content of the educational interventions, including an assessment of validation of the intervention, hindered the generalizability of findings. Issues such as the educational background, years of experience, and hours of clinical training of the staff may also affect the type and effectiveness of the intervention. Whether these interventions are sustainable in time or should be periodically repeated are also issues that should be addressed in future studies, especially taking into consideration two studies in this review [29,31], since their conclusions showed that low CLABSI rates can only be sustained with repeated and continued infection prevention education.

\section{Limitations}

The current study has certain limitations. We included studies in the English language only, and hence data from studies in other languages may be missing. The studies were very heterogeneous and we were unable to determine the most effective type of education intervention for CLABSI rates. We only analyzed studies pertaining to ICU settings, and hence our findings cannot be generalized to other settings. Moreover, we only included studies that assessed CLABSI rates and rejected other definitions for bloodstream infections associated with CVC.

\section{Conclusions}

This systematic review identified several educational interventions capable of reducing CLABSI rates, either in combination or alone. However, to maintain reduced CLABSI rates post-intervention, regular follow-ups, resource support, and multifaceted cooperative approaches may be essential.

\section{Additional Information \\ Disclosures}

Conflicts of interest: In compliance with the ICMJE uniform disclosure form, all authors declare the following: Payment/services info: All authors have declared that no financial support was received from any organization for the submitted work. Financial relationships: All authors have declared that they have no financial relationships at present or within the previous three years with any organizations that might have an interest in the submitted work. Other relationships: All authors have declared that there are no other relationships or activities that could appear to have influenced the submitted work.

\section{Acknowledgements}

Special thanks to Dr. Stelios Iordanou for his valuable contribution.

\section{References}

1. Blot K, Bergs J, Vogelaers D, Blot S, Vandijck D: Prevention of central line-associated bloodstream infections through quality improvement interventions: a systematic review and meta-analysis. Clin Infect Dis. 2014, 59:96-105. 10.1093/cid/ciu239

2. Center for Disease Control and Prevention: bloodstream infection event (central line-associated bloodstream infection and non-central line-associated Bloodstream Infection). (2016). Accessed: August 18, 2021: http://www.cdc.gov/nhsn/.

3. Blot SI, Depuydt P, Annemans L, et al.: Clinical and economic outcomes in critically ill patients with nosocomial catheter-related bloodstream infections. Clin Infect Dis. 2005, 41:1591-8. 10.1086/497833 
4. Halton KA, Cook D, Paterson DL, Safdar N, Graves N: Cost-effectiveness of a central venous catheter care bundle. PLoS One. 2010, 5:e12815. 10.1371/journal.pone.0012815

5. Burden AR, Torjman MC, Dy GE, et al.: Prevention of central venous catheter-related bloodstream infections: is it time to add simulation training to the prevention bundle? J Clin Anesth. 2012, 24:555-60. 10.1016/j.jclinane.2012.04.006

6. Higuera F, Rangel-Frausto MS, Rosenthal VD, et al.: Attributable cost and length of stay for patients with central venous catheter-associated bloodstream infection in Mexico City intensive care units: a prospective, matched analysis. Infect Control Hosp Epidemiol. 2007, 28:31-5. 10.1086/510812

7. Rosenthal VD, Guzman S, Migone O, Crnich CJ: The attributable cost, length of hospital stay, and mortality of central line-associated bloodstream infection in intensive care departments in Argentina: a prospective, matched analysis. Am J Infect Control. 2003, 31:475-80. 10.1016/j.ajic.2003.03.002

8. Pronovost P, Needham D, Berenholtz S, et al.: An intervention to decrease catheter-related bloodstream infections in the ICU. N Engl J Med. 2006, 355:2725-32. 10.1056/NEJMoa061115

9. Bion J, Richardson A, Hibbert P, et al.: 'Matching Michigan': a 2-year stepped interventional programme to minimise central venous catheter-blood stream infections in intensive care units in England. BMJ Qual Saf. 2013, 22:110-23. 10.1136/bmjqs-2012-001325

10. Iordanou S, Middleton N, Papathanassoglou E, Palazis L, Raftopoulos V: Should the CDC's recommendations for promptly removing unnecessary centrally inserted central catheters be enhanced? Ultrasound-guided peripheral venous cannulation to fully comply. J Vasc Access. 2020, 21:86-91. $10.1177 / 1129729819863556$

11. Rosenthal VD, Maki DG, Mehta Y, et al.: International Nosocomial Infection Control Consortium (INICC) report, data summary of 43 countries for 2007-2012. Device-associated module. Am J Infect Control. 2014, 42:942-56. 10.1016/j.ajic.2014.05.029

12. Yokoe DS, Anderson DJ, Berenholtz SM, et al.: A compendium of strategies to prevent healthcare-associated infections in acute care hospitals: 2014 updates. Infect Control Hosp Epidemiol. 2014, 35:S21-31. 10.1017/s0899823x00193833

13. O'Grady NP, Alexander M, Burns LA, et al.: Guidelines for the prevention of intravascular catheter-related infections. Clin Infect Dis. 2011, 52:e162-93. 10.1093/cid/cir257

14. Maki DG, Kluger DM, Crnich CJ: The risk of bloodstream infection in adults with different intravascular devices: a systematic review of 200 published prospective studies. Mayo Clin Proc. 2006, 81:1159-71. 10.4065/81.9.1159

15. Blot S, Vandijck D, Vogelaers D, Labeau S: Bridging the gap between theory and practice . ICU Manag Pract. 2011, 11:5-8.

16. Cabana MD, Rand CS, Powe NR, Wu AW, Wilson MH, Abboud PAC, Rubin HR: Why don’t physicians follow clinical practice guidelines? A framework for improvement. Pediatr Res. 1999, 45:121. 10.1203/00006450199904020-00719

17. Dedunska K, Dyk D: Prevention of central venous catheter-associated bloodstream infections: a questionnaire evaluating the knowledge of the selected 11 evidence-based guidelines by Polish nurses. Am J Infect Control. 2015, 43:1368-71. 10.1016/j.ajic.2015.07.022

18. Slim K, Nini E, Forestier D, Kwiatkowski F, Panis Y, Chipponi J: Methodological index for non-randomized studies (minors): development and validation of a new instrument. ANZ J Surg. 2003, 73:712-6. 10.1046/j.1445-2197.2003.02748.x

19. Exline MC, Ali NA, Zikri N, et al.: Beyond the bundle--journey of a tertiary care medical intensive care unit to zero central line-associated bloodstream infections. Crit Care. 2013, 17:R41. 10.1186/cc12551

20. Render ML, Hasselbeck R, Freyberg RW, Hofer TP, Sales AE, Almenoff PL: Reduction of central line infections in Veterans Administration intensive care units: an observational cohort using a central infrastructure to support learning and improvement. BMJ Qual Saf. 2011, 20:725-32. 10.1136/bmjqs.2010.048462

21. Ong A, Dysert K, Herbert C, et al.: Trends in central line-associated bloodstream infections in a traumasurgical intensive care unit. Arch Surg. 2011, 146:302-7. 10.1001/archsurg.2011.9

22. Barsuk JH, Cohen ER, Feinglass J, McGaghie WC, Wayne DB: Use of simulation-based education to reduce catheter-related bloodstream infections. Arch Intern Med. 2009, 169:1420-3. 10.1001/archinternmed.2009.215

23. Guerin K, Wagner J, Rains K, Bessesen M: Reduction in central line-associated bloodstream infections by implementation of a postinsertion care bundle. Am J Infect Control. 2010, 38:430-3. 10.1016/j.ajic.2010.03.007

24. Galpern D, Guerrero A, Tu A, Fahoum B, Wise L: Effectiveness of a central line bundle campaign on lineassociated infections in the intensive care unit. Surgery. 2008, 144:492-5. 10.1016/j.surg.2008.06.004

25. Coopersmith CM, Zack JE, Ward MR, et al.: The impact of bedside behavior on catheter-related bacteremia in the intensive care unit. Arch Surg. 2004, 139:131-6. 10.1001/archsurg.139.2.131

26. Warren DK, Zack JE, Mayfield JL, Chen A, Prentice D, Fraser VJ, Kollef MH: The effect of an education program on the incidence of central venous catheter-associated bloodstream infection in a medical ICU. Chest. 2004, 126:1612-8. 10.1378/chest.126.5.1612

27. Walz JM, Ellison RT 3rd, Mack DA, et al.: The bundle "plus": the effect of a multidisciplinary team approach to eradicate central line-associated bloodstream infections. Anesth Analg. 2015, 120:868-76. 10.1213/ANE.0b013e3182a8b01b

28. Marra AR, Cal RG, Durão MS, et al.: Impact of a program to prevent central line-associated bloodstream infection in the zero tolerance era. Am J Infect Control. 2010, 38:434-9. 10.1016/j.ajic.2009.11.012

29. Lobo RD, Levin AS, Oliveira MS, et al.: Evaluation of interventions to reduce catheter-associated bloodstream infection: continuous tailored education versus one basic lecture. Am J Infect Control. 2010, 38:440-8. 10.1016/j.ajic.2009.09.013

30. Santana SL, Furtado GH, Wey SB, Medeiros EA: Impact of an education program on the incidence of central line-associated bloodstream infection in 2 medical-surgical intensive care units in Brazil. Infect Control Hosp Epidemiol. 2008, 29:1171-3. 10.1086/591862 
31. Park SW, Ko S, An HS, Bang JH, Chung WY: Implementation of central line-associated bloodstream infection prevention bundles in a surgical intensive care unit using peer tutoring. Antimicrob Resist Infect Control. 2017, 6:103. 10.1186/s13756-017-0263-3

32. Mazi W, Begum Z, Abdulla D, Hesham A, Maghari S, Assiri A, Senok A: Central line-associated bloodstream infection in a trauma intensive care unit: impact of implementation of Society for Healthcare Epidemiology of America/Infectious Diseases Society of America practice guidelines. Am J Infect Control. 2014, 42:865-7. 10.1016/j.ajic.2014.05.005

33. Khalid I, Al Salmi H, Qushmaq I, Al Hroub M, Kadri M, Qabajah MR: Itemizing the bundle: achieving and maintaining "zero" central line-associated bloodstream infection for over a year in a tertiary care hospital in Saudi Arabia. Am J Infect Control. 2013, 41:1209-13. 10.1016/j.ajic.2013.05.028

34. Hansen S, Schwab F, Schneider S, Sohr D, Gastmeier P, Geffers C: Time-series analysis to observe the impact of a centrally organized educational intervention on the prevention of central-line-associated bloodstream infections in 32 German intensive care units. J Hosp Infect. 2014, 87:220-6. 10.1016/j.jhin.2014.04.010

35. Azim A, Acharya R, Mishra SB, Ipsita S: Impact of nursing education on CLABSI rates: an experience from a tertiary care hospital in Eastern India. Indian J Crit Care Med. 2019, 23:316-9. 10.5005/jp-journals-1007123205

36. Jaggi N, Rodrigues C, Rosenthal VD, et al.: Impact of an international nosocomial infection control consortium multidimensional approach on central line-associated bloodstream infection rates in adult intensive care units in eight cities in India. Int J Infect Dis. 2013, 17:e1218-24. 10.1016/j.ijid.2013.07.007

37. Leblebicioglu H, Ersoz G, Rosenthal VD, et al.: Impact of a multidimensional infection control approach on catheter-associated urinary tract infection rates in adult intensive care units in 10 cities of Turkey: International Nosocomial Infection Control Consortium findings (INICC). Am J Infect Control. 2013, 41:88591. 10.1016/j.ajic.2013.01.028

38. Ilan R, Doan J, Cload B, Squires M, Day A: Removing nonessential central venous catheters: evaluation of a quality improvement intervention. Can J Anaesth. 2012, 59:1102-10. 10.1007/s12630-012-9794-5

39. Paquet F, Morlese J, Frenette C: Use of dry dressings for central venous access devices (CVADs) to decrease central line-associated blood stream infections (CLABSI) in a trauma intensive care unit (ICU). Br J Nurs. 2021, 30:S37-42. 10.12968/bjon.2021.30.8.S37

40. Allen GB, Miller V, Nicholas C, et al.: A multitiered strategy of simulation training, kit consolidation, and electronic documentation is associated with a reduction in central line-associated bloodstream infections. Am J Infect Control. 2014, 42:643-8. 10.1016/j.ajic.2014.02.014

41. Pérez Parra A, Cruz Menárguez M, Pérez Granda MJ, Tomey MJ, Padilla B, Bouza E: A simple educational intervention to decrease incidence of central line-associated bloodstream infection (CLABSI) in intensive care units with low baseline incidence of CLABSI. Infect Control Hosp Epidemiol. 2010, 31:964-7. $10.1086 / 655841$

42. Alkhawaja S, Saeed NK, Rosenthal VD, et al.: Impact of International Nosocomial Infection Control Consortium's multidimensional approach on central line-associated bloodstream infection rates in Bahrain. J Vasc Access. 2020, 21:481-9. 10.1177/1129729819888426

43. Rosenthal VD, Desse J, Maurizi DM, et al.: Impact of the International Nosocomial Infection Control Consortium (INICC)'s multidimensional approach on rates of central line-associated bloodstream infection in 14 intensive care units in 11 hospitals of 5 cities in Argentina. Infect Control Hosp Epidemiol. 2018, 39:445-51. 10.1017/ice.2017.298

44. Rosenthal VD, Maki DG, Rodrigues C, et al.: Impact of International Nosocomial Infection Control Consortium (INICC) strategy on central line-associated bloodstream infection rates in the intensive care units of 15 developing countries. Infect Control Hosp Epidemiol. 2010, 31:1264-72. 10.1086/657140

45. Van T, Annis AM, Yosef M, et al.: Nurse staffing and healthcare-associated infections in a national healthcare system that implemented a nurse staffing directive: multi-level interrupted time series analyses. Int J Nurs Stud. 2020, 104:103531. 10.1016/j.ijnurstu.2020.103531 